Research Article

\title{
$\alpha$-Ketoglutarate Accumulation Is Not Dependent on Isocitrate Dehydrogenase Activity during Tellurite Detoxification in Escherichia coli
}

\author{
Claudia A. Reinoso, ${ }^{1}$ Vasu D. Appanna, ${ }^{2}$ and Claudio C. Vásquez ${ }^{1}$ \\ ${ }^{1}$ Departamento de Biología, Facultad de Química y Biología, Universidad de Santiago de Chile, \\ Santiago 9170000, Chile \\ ${ }^{2}$ Department of Chemistry and Biochemistry, Laurentian University, Sudbury, ON, Canada P3E 2C6 \\ Correspondence should be addressed to Claudio C. Vásquez; claudio.vasquez@usach.cl
}

Received 25 July 2013; Revised 26 October 2013; Accepted 29 October 2013

Academic Editor: Michele Rechia Fighera

Copyright ( 2013 Claudia A. Reinoso et al. This is an open access article distributed under the Creative Commons Attribution License, which permits unrestricted use, distribution, and reproduction in any medium, provided the original work is properly cited.

\begin{abstract}
Tellurite is toxic to most microorganisms because of its ability to generate oxidative stress. However, the way in which tellurite interferes with cellular processes is not fully understood to date. In this line, it was previously shown that tellurite-exposed cells displayed reduced activity of the $\alpha$-ketoglutarate dehydrogenase complex ( $\alpha$-KGDH), which resulted in $\alpha$-ketoglutarate ( $\alpha$-KG) accumulation. In this work, we assessed if $\alpha$-KG accumulation in tellurite-exposed $E$. coli could also result from increased isocitrate dehydrogenase (ICDH) and glutamate dehydrogenase (GDH) activities, both enzymes involved in $\alpha$-KG synthesis. Unexpectedly both activities were found to decrease in the presence of the toxicant, an observation that seems to result from the decreased transcription of $i c d A$ and $g d h A$ genes (encoding ICDH and GDH, resp.). Accordingly, isocitrate levels were found to increase in tellurite-exposed E. coli. In the presence of the toxicant, cells lacking $i c d A$ or $g d h A$ exhibited decreased reactive oxygen species (ROS) levels and higher tellurite sensitivity as compared to the wild type strain. Finally, a novel branch activity of ICDH as tellurite reductase is presented.
\end{abstract}

\section{Introduction}

Tellurium is a metalloid belonging to the chalcogen group of the Periodic Table of elements and is found in elemental $\left(\mathrm{Te}^{0}\right)$, inorganic [telluride $\left(\mathrm{Te}^{2-}\right)$, tellurite $\left(\mathrm{TeO}_{3}{ }^{2-}\right)$, tellurate $\left(\mathrm{TeO}_{4}{ }^{2-}\right)$ ] and organic [dimethyl telluride $\left(\mathrm{CH}_{3} \mathrm{TeCH}_{3}\right)$, dimethyl ditelluride $\left(\mathrm{CH}_{3} \mathrm{TeTeCH}_{3}\right)$ ] forms [1].

In particular, tellurite is toxic for most living organisms because of its ability to generate oxidative stress. This was first demonstrated in Escherichia coli exposed to the toxicant, where increased levels of intracellular reactive oxygen species (ROS), particularly superoxide, were observed [2-6]. With the exception of glutathione [7], most intracellular tellurite targets are still poorly understood. Nevertheless, it has been established that tellurite-exposed E. coli results in decreased activity of certain ROS-sensitive enzymes from the Krebs cycle such as aconitase and fumarase [3,8]. Furthermore,
Pseudomonas fluorescens and HepG2 cells exposed to ROSproducing metals exhibit decreased $\alpha$-ketoglutarate dehydrogenase $(\alpha-\mathrm{KGDH})$ and increased isocitrate dehydrogenase (ICDH) activity. These conditions result in $\alpha$-ketoglutarate $(\alpha-\mathrm{KG})$ accumulation, Krebs cycle disruption, and decreased NADH and ATP levels, suggesting that $\alpha$-KG may be involved in the cellular response to these ROS elicitors [9]. $\alpha$-KG accumulation, as consequence of enhanced glutamate dehydrogenase (GDH) activity, was also observed in menadioneexposed P. fluorescens [10].

On the other hand, hydrogen peroxide oxidizes $\alpha$-keto acids yielding $\mathrm{CO}_{2}$ and water [12], a reaction underlying the cytoprotective effect of $\alpha$-keto acids such as pyruvate and $\alpha$-KG [13]. These molecules also protect against tertbutyl hydroperoxide (tert-BuOOH) induced oxidative damage [14]. 
TABLE 1: E. coli strains and primers.

\begin{tabular}{|c|c|c|}
\hline Strain & Relevant genotype & Reference \\
\hline BW25113 & lacIq rrnB $\triangle$ lacZ hsdR514 $\triangle a r a B A D \triangle r h a B A D$ & {$[11]$} \\
\hline$\Delta g d h A$ & BW25113 $\Delta g d h A(g d h A:: k a n)$ & [11] \\
\hline$\Delta i c d A$ & BW25113 $\Delta i c d A(i c d A:: k a n)$ & {$[11]$} \\
\hline$\triangle \operatorname{sod} A B$ & $\begin{array}{l}\mathrm{DE}(\text { lac }) 4169 \text { rpsL DE }(\text { sodA-lacZ) } 49 \\
\mathrm{DE}(\text { sodB-kan }) 1-\mathrm{DE}(2) \mathrm{Cam}^{\mathrm{R}} \mathrm{Kan}^{\mathrm{R}}\end{array}$ & [11] \\
\hline$i c d A p C A 24 \mathrm{~N}$ & BW25113 carrying pCA24N & [11] \\
\hline Primers & Forward $(\mathrm{F})$ or reverse $(\mathrm{R})$, to amplify & $5^{\prime}-3^{\prime}$ sequence \\
\hline$g d h A \mathrm{~F}$ & $\mathrm{~F}, g d h A$ & CATATTCTCTGGAGTCATTCCTCA \\
\hline$g d h A \mathrm{R}$ & $\mathrm{R}, g d h A$ & ATCATCAACCCA TACCACGC \\
\hline$i c d A \mathrm{~F}$ & $\mathrm{~F}, i c d A$ & TCCGGCACAAGGCAAGAAGA \\
\hline$i c d A \mathrm{R}$ & $\mathrm{R}, i c d A$ & CAGCCAGACGTCCTGACCAT \\
\hline
\end{tabular}

In addition to decreasing ROS, hydrogen peroxidemediated $\alpha$-KG oxidative decarboxylation helps to compensate succinate levels upon $\alpha$-KGDH complex inhibition during oxidative stress, thus alleviating the Krebs cycle function [15]. In this context, decreased $\alpha$-KGDH activity and consequently increased $\alpha-\mathrm{KG}$ content were observed in tellurite-exposed E. coli [16]. However, $\alpha$-KG accumulation could also result from increased ICDH and/or GDH activity. ICDH catalyzes the oxidative decarboxylation of isocitrate to $\alpha-\mathrm{KG}$ yielding the important reducing equivalent NADPH [17]. In most bacteria, ICDH is a dimeric enzyme consisting of identical subunits with a molecular mass of $\sim 45 \mathrm{kDa}$ [18]. $\mathrm{NADPH}$ is also essential for regenerating reduced glutathione (GSH) by glutathione reductase [19], an important reaction protecting cells from oxidative damage. In this context, ICDH could also play an antioxidant role during oxidative stress [20]. In turn, GDH catalyzes the reversible reductive amination of $\alpha$-KG to yield glutamate. In E. coli, the enzyme consists of six identical polypeptides [21].

This work was undertaken to analyze if the $\alpha$-KG-synthesizing enzymes ICDH and GDH were responsible or not for the increased $\alpha$-KG levels observed in tellurite-exposed E. coli.

\section{Materials and Methods}

2.1. Bacteria, Growth Conditions, Toxicant Tolerance and Isocitrate Content Determination. Bacterial strains used in this work are listed in Table 1 . Cells were routinely grown in Luria-Bertani (LB) or M9 minimal medium [22] at $37^{\circ} \mathrm{C}$ with shaking. Growth was started by inoculating 1:100 dilutions of overnight cultures into fresh medium. When required, kanamycin $(100 \mu \mathrm{g} / \mathrm{mL})$ was amended to the medium. Growth inhibition zones (GIZ), minimal inhibitory concentrations (MIC), and intracellular isocitrate levels were determined as described previously for $\alpha$-KG [16]. Protein concentration was determined as described by Bradford [23].

2.1.1. $q R T-P C R$. Cells were grown in $\mathrm{LB}$ medium to $\mathrm{OD}_{600} \sim$ 0.5 and exposed to $0.5 \mu \mathrm{g} / \mathrm{mL}$ tellurite $(30 \mathrm{~min}$ ). Total RNA was purified using the RNAsy kit (Qiagen) as recommended.
Two $\mu$ g of purified RNA was used as template and reactions were carried out using the LightCycler RNA Amplification SYBR Green I kit (Roche Applied Science). Specific primers used are indicated in Table 1. Transcript amounts (ng) of $g d h A$ and icdA mRNA were calculated using standard curves made with known template concentrations. rpoD mRNA was used as the housekeeping gene for normalization.

2.2. ROS Monitoring by Flow Cytometry. E. coli BW25113, $\triangle g d h A$, and $\triangle i c d A$ strains grown to $\mathrm{OD}_{600} \sim 0.5$ were exposed to $0.05 \mu \mathrm{g} / \mathrm{mL}$ tellurite for $30 \mathrm{~min}$ to determine total ROS. After washing, centrifuging, and suspending in $500 \mu \mathrm{L}$ of $25 \mathrm{mM}$ phosphate buffer $\mathrm{pH} 7.0$ (buffer A), cells were incubated for $30 \mathrm{~min}$ in the dark with $0.02 \mathrm{mM}$ 2,7 dihydrodichlorofluorescein diacetate $\left(\mathrm{H}_{2} \mathrm{DCFDA}\right)$. Fluorescence intensity $\left(\lambda_{\text {ex }} 428, \lambda_{\text {em }}\right.$ 522) was monitored as described previously [16]. Cells exposed to $5 \mathrm{mM}$ TBH (tert-butyl hydroperoxide) were used as positive control of oxidative stress.

To assess superoxide, the referred strains were grown to $\mathrm{OD}_{600} \sim 0.5$ and exposed to $0.05 \mu \mathrm{g} / \mathrm{mL}$ tellurite for $30 \mathrm{~min}$. After centrifuging and washing with buffer A, cells were suspended in $500 \mu \mathrm{L}$ of buffer A and incubated in the dark for $15 \mathrm{~min}$ with $0.05 \mathrm{mM}$ dihydroethidine (DHE). Intensity was assessed using a Becton Dickinson (model FacsCanto II) apparatus equipped with an Argon laser $\left(\lambda_{\mathrm{ex}} 520, \lambda_{\mathrm{em}} 610\right)$. Tellurite-exposed $\Delta$ sodAsodB E. coli was used as control.

2.3. Determination of Enzymatic Activity. GDH was assayed in cell-free extracts from tellurite-exposed $E$. coli $(0.5 \mu \mathrm{g} / \mathrm{mL}$, $30 \mathrm{~min}$ ) at $37^{\circ} \mathrm{C} . \mathrm{NADP}^{+}$reduction was monitored at $340 \mathrm{~nm}$ for $1 \mathrm{~min}$. The reaction mixture $(1 \mathrm{~mL})$ contained $25 \mathrm{mM}$ Tris$\mathrm{HCl}$ buffer, $\mathrm{pH}$ 7.0, $0.5 \mathrm{mM} \mathrm{NADP}^{+}$and $10 \mathrm{mM}$ glutamate. Assays were started with the extract ( $100 \mu \mathrm{g}$ protein). Blue native polyacrylamide gels were run for in-gel visualization of enzyme activity, coupling NADH/NADPH formation to $0.3 \mathrm{mg} / \mathrm{mL}$ phenazine methosulfate and $0.5 \mathrm{mg} / \mathrm{mL}$ iodonitrotetrazolium as described [24].

$\mathrm{ICDH}$ was assessed at $37^{\circ} \mathrm{C}$ in cell-free extracts from tellurite-exposed E. coli $(0.5 \mu \mathrm{g} / \mathrm{mL}, 30 \mathrm{~min})$. Blue native polyacrylamide gels were run and incubated with $25 \mathrm{mM}$ Tris- $\mathrm{HCl}$ pH 7.4 buffer containing $5 \mathrm{mM} \mathrm{MgCl}_{2}$ for $15 \mathrm{~min}$. 
To visualize ICDH activity, gels were immersed into a solution containing $5 \mathrm{mM}$ isocitrate and $0.5 \mathrm{mM} \mathrm{NADP}^{+}$. Enzymatic activity was detected in gels by formazan precipitation from $0.4 \mathrm{mg} / \mathrm{mL}$ iodonitrotetrazolium and $0.2 \mathrm{mg} / \mathrm{mL}$ phenazine methosulfate [24].

Tellurite reductase (TR) activity associated to ICDH was determined by fractionating $100 \mu \mathrm{g}$ protein through nondenaturing polyacrylamide gel electrophoresis. After the run, gels were washed, immersed into a solution that contained $1 \mathrm{mM} \mathrm{K}_{2} \mathrm{TeO}_{3}$ and $1 \mathrm{mM} \mathrm{NADH}$, and incubated at $37^{\circ} \mathrm{C}$.

2.4. Data Analysis. In general, results were expressed as the mean \pm the standard deviation. Differences between experimental groups were analyzed using one-way ANOVA. $P$ values $<0.05$ were considered statistically significant.

\section{Results and Discussion}

In spite of many efforts, the overall effects of tellurite in $\mathrm{TeO}_{3}{ }^{2-}$-exposed cells are not fully understood to date. In this context, some work has been done to unveil the toxicant's effect on several bacterial metabolic pathways [5]. Important data were obtained while studying the interaction of tellurite with the electron transport chain via the DsbB link to the quinone pool in Rhodobacter capsulatus [25]. Shortly after that, it was communicated that the E3 component (dihydrolipoyl dehydrogenase) of the E. coli pyruvate dehydrogenase complex is able to reduce tellurite to its elemental, metallic form [26]. More recently, it was shown that telluriteexposed E. coli exhibits decreased activity of the key glycolytic enzymes pyruvate kinase $(\mathrm{PK})$ and phosphofructokinase (PFK) [27]. However, not much is known about tellurite effects on the Krebs cycle. Some minor data regarding dissipation of the transmembrane $\Delta \mathrm{pH}$ gradient resulting in lower ATP levels in tellurite-exposed E. coli [28] and inactivation of fumarase and aconitase [8] have been published.

3.1. Effects of Tellurite on E. coli ICDH and GDH Activity and $g d h A$ and icdA Gene Transcription. Previous work showed that $\alpha-K G$ accumulates in response to $E$. coli exposure to tellurite [16]. Since accumulation of this $\alpha$-keto acid could also result from increased ICDH and/or GDH activities, these enzymes were analyzed in cell-free extracts from telluriteexposed wild type E. coli. After fractionation by native PAGE, in situ activity assays showed a significant decrease of ICDH activity, as seen previously for $\alpha$-KGDH [16] (Figure 1(a)). Using the same experimental approach, GDH activity was also found severely decreased ( 70\%) (Figure 1(b)). None of these activities were recovered after exposing E. coli to tellurite for $24 \mathrm{~h}$. These results clearly show that $\alpha$-KG accumulation does not result from an increase of these activities. Decreased ICDH activity has also been observed in cells exposed to nitric oxide [29], peroxynitrite [30], ROS [31], and lipid peroxidation products $[29,32]$. In vitro experiments with purified $\mathrm{ICDH}$ also demonstrated that it loses activity if exposed to $\mathrm{H}_{2} \mathrm{O}_{2}$, superoxide or hydroxyl radicals, and photochemically-generated singlet oxygen [31, 33]. In this

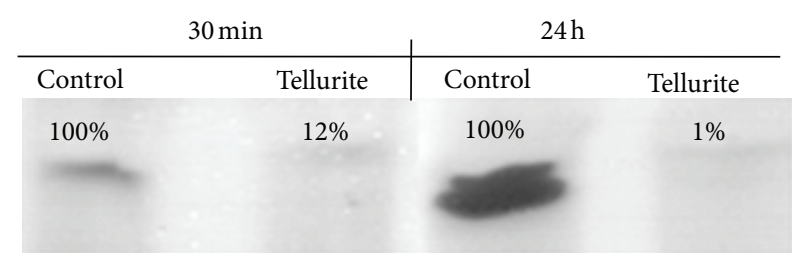

(a)

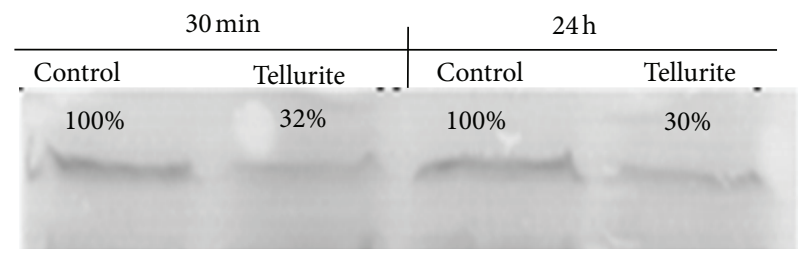

(b)

\begin{tabular}{|c|c|}
\hline Gene & Relative expression \\
\hline$g d h A$ & $0.4 \pm 0.07$ \\
\hline$i c d A$ & $0.6 \pm 0.13$ \\
\hline
\end{tabular}

(c)

FIGURE 1: In situ ICDH and GDH activity and transcriptional level of $g d h A$ and $i c d A$ genes in tellurite-exposed E. coli. ICDH (a) and (b) GDH activity was assayed after fractionating extracts from telluritetreated cells by native gradient polyacrylamide gels as described in methods. Representative gels are shown. (c) Transcriptional level of $g d h A$ and $i c d A$ genes in tellurite-exposed E. coli. Numbers represent the mean of 3 independent trials. The relative expression was normalized to that of the rpoD gene.

context, the decreased ICDH activity observed in telluriteexposed $E$. coli could be a consequence of the superoxide anion that is generated during tellurite reduction in $\mathrm{TeO}_{3}{ }^{2-}$ exposed cells $[3,8]$. Although it has been shown that GDH activity declines with $\mathrm{H}_{2} \mathrm{O}_{2}$ [34], it is too preliminary to assign this enzyme some responsibility in $\alpha$-KG intracellular accumulation in the presence of tellurite. In this line, the increased $\mathrm{H}_{2} \mathrm{O}_{2}$ levels detected in $\mathrm{TeO}_{3}{ }^{2-}$-exposed cells could explain the observed decrease of GDH activity.

To test if the observed decrease of ICDH and GDH activities was reflected at the transcriptional level, qRT-PCR assays were carried out as described in Methods. Results showed that icdA and $g d h A$ expression was repressed in tellurite-exposed E. coli (Figure 1(c)), suggesting that tellurite effects may occur at the protein level or as a consequence of $\alpha-\mathrm{KG}$ accumulation.

One would expect that a decrease of ICDH activity results in isocitrate accumulation. This was precisely the case; that is, this tricarboxylic acid accumulates quickly after tellurite exposure (Figure 2(a)). Another enzyme that could help to explain isocitrate accumulation is isocitrate lyase (ICL), which catalyzes the reversible reaction isocitrate $\leftrightarrow$ glyoxylate + succinate [35]. Conversely to the increased ICL observed in aluminium-exposed $P$. fluorescens [36], ICL decreased in tellurite-exposed E. coli supporting the idea that isocitrate accumulation could also result from decreased ICL activity (unpublished data). Thus, the activity of some enzymes from the Krebs cycle decreases in the presence of the toxicant, 
TABLE 2: Tellurite growth inhibition zone (GIZ) and minimal inhibitory concentration (MIC) for the indicated E. coli strains.

\begin{tabular}{|c|c|c|c|c|}
\hline \multirow{3}{*}{ Strain } & \multicolumn{2}{|c|}{$\operatorname{GIZ}\left(\mathrm{cm}^{2}\right)$} & \multicolumn{2}{|c|}{$\mathrm{MIC}(\mu \mathrm{g} / \mathrm{mL})$} \\
\hline & \multicolumn{4}{|c|}{ Culture medium } \\
\hline & LB & M9 & LB & M9 \\
\hline BW25113 & $7.12 \pm 0.3$ & $4.91 \pm 0.05$ & $0.8 \pm 0.09$ & $12 \pm 0.89$ \\
\hline$\Delta i c d A$ & $8.81 \pm 0.1$ & $7.63 \pm 0.2$ & $0.2 \pm 0.03$ & $2 \pm 0.22$ \\
\hline$\Delta g d h A$ & $8.24 \pm 0.05$ & $6.6 \pm 0.2$ & $0.2 \pm 0.03$ & $2 \pm 0.22$ \\
\hline
\end{tabular}

Numbers represent the mean of 3 independent trials \pm SD.

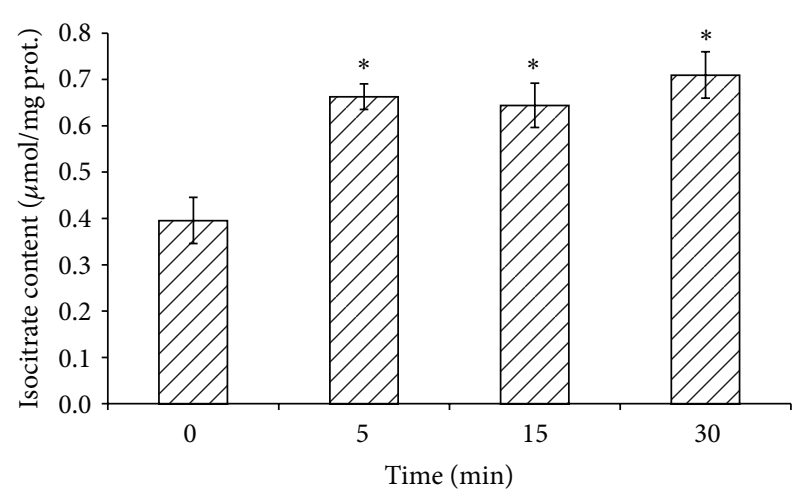

(a)

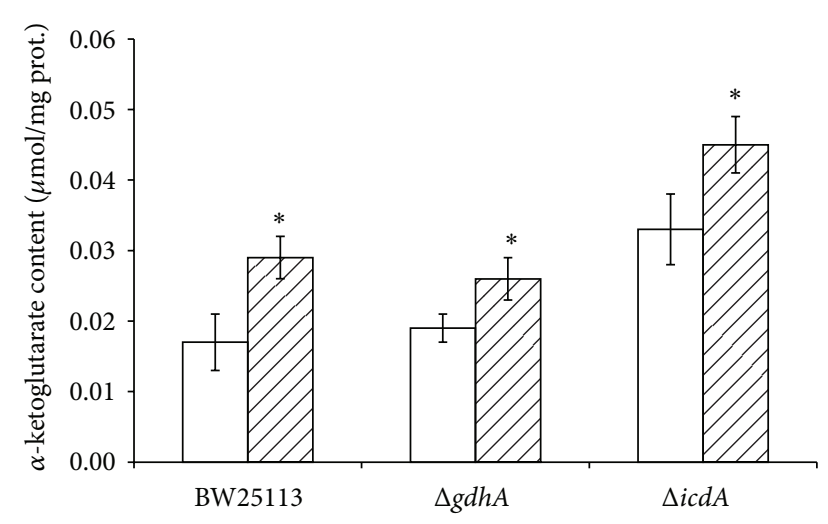

\begin{tabular}{|l}
$\square$ \\
-tellurite \\
+tellurite
\end{tabular}

(b)

FIGURE 2: Isocitrate and $\alpha$-KG content in tellurite-exposed E. coli. (a), Isocitrate content was assessed by HPLC in extracts from wild type E. coli previously exposed to $0.5 \mu \mathrm{g} / \mathrm{mL}$ tellurite for 5,15 and $30 \mathrm{~min}$ as described in Methods. Numbers represent the mean of 3 independent trials $\pm \mathrm{SD}$. ${ }^{*} P<0.005$. (b), $\alpha$-KG content in $E$. coli previously grown in LB medium. $\alpha$-KG content was determined by HPLC in cell-free extracts of the indicated $E$. coli strains as described in Methods. Bars represent the standard deviation $(n=3) .{ }^{*} P<$ 0.005 .

which in turn may explain the decrease of ATP levels in tellurite-exposed E. coli [28].

3.2. ICDH Displays Tellurite Reductase (TR) Activity. Regarding bacterial tellurite resistance and given that some dehydrogenases such as pyruvate dehydrogenase $(\mathrm{PDH})$ exhibit a branch activity related to $\mathrm{Te}^{4+} \rightarrow \mathrm{Te}^{0}$ reduction [26] it was interesting to test if ICDH also displayed such a TR activity. ICDH's TR activity was observed either in plaque assays or after fractionation by native PAGE (Figures 3(a) and $3(\mathrm{~b})$ ). If the ICDH ability to reduce tellurite is related or not to the observed decrease of ICDH activity is not yet fully understood. Maybe ICDH's TR activity could be activated to eliminate tellurite, but also decreased ICDH activitymediated isocitrate accumulation could act as a signal to decrease the efficiency of the Krebs cycle to limit NADH generation and thus ROS production in the presence of the toxicant.

3.3. Tellurite Tolerance and ROS Generation in $\triangle g d h A$ and $\triangle i c d A$ Strains. Since ICDH and GDH activities decrease and $\alpha$-KG accumulates in tellurite-exposed $E$. coli, it was interesting to determine tellurite tolerance in strains lacking the $i c d A$ or $g d h A$ gene. Toxicant tolerance was assessed by determining growth inhibition zones (GIZ) and minimal inhibitory concentrations (MIC). Both mutant strains showed greater sensitivity to tellurite than the isogenic, parental, wild type strain (Table 2). This higher sensitivity is most probably due to the metabolic changes occurring in the absence of the referred genes. In fact and regarding the $\Delta i c d A$ strain, delayed growth and decreased glucose consumption along with declined generation of NADPH and ATP have been observed [37]. Since it is expected that $\alpha$ KG accumulation protects against oxidative stress, total ROS and superoxide were assessed in tellurite-exposed $E$. coli strains by flow cytometry using $\mathrm{H}_{2}$ DCFDA [38, 39] and DHE [38] probes, respectively. In general and irrespective of the culture medium, all tested strains showed increased ROS and superoxide levels in the presence of tellurite. Lower ROS and superoxide levels observed in $\Delta i c d A$ (Figure 4 and Figures S1-S4) are most probably explained because these cells accumulate higher amounts of $\alpha$-KG than the parental strain (Figure 2(b)).

Since $\alpha$-KG levels can also increase by means of aspartate aminotransferase (L-aspartate $+\alpha-\mathrm{KG} \leftrightarrow$ oxaloacetate $+\mathrm{L}$ glutamate [40] and/or glutamate synthase (L-glutamine $+\alpha$ $\mathrm{KG}+\mathrm{NADPH}+\mathrm{H}^{+} \leftrightarrow 2$ L-glutamate $+\mathrm{NADP}^{+}$[41], experiments aiming to address the participation of these enzymes in $\alpha$-KG accumulation in tellurite-exposed cells are under way in our laboratory.

Finally, the results from this work and from other groups regarding this issue are summarized in Scheme 1. Once tellurite enters the cell, it becomes reduced by a number of tellurite reductases (TRs) such as ICDH and E3 (from $\alpha-\mathrm{KGDH}$ or 


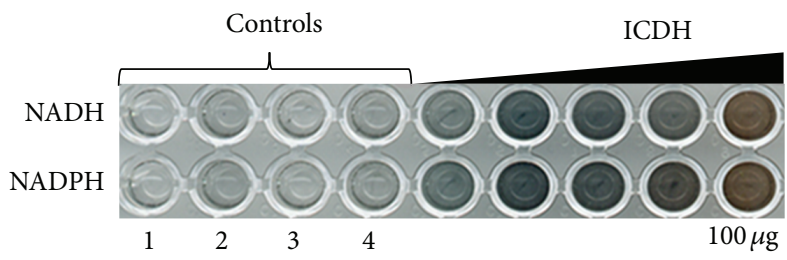

(a)

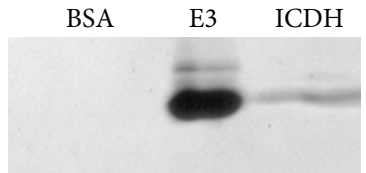

(b)

FIGURE 3: ICDH's tellurite reductase activity. (a) TR activity determined by plaque assay. Controls are (1) only buffer, (2) buffer $+1 \mathrm{mM} \beta$ mercapto ethanol ( $\beta$-ME), (3) buffer $+\beta-\mathrm{ME}+1 \mathrm{mM}$ tellurite, and (4) buffer $+\beta \mathrm{ME}+$ tellurite + bovine serum albumin (BSA). Purified ICDH was added at 5, 10, 25, 50, and $100 \mu \mathrm{g}$, as indicated in the figure. (b) TR activity was revealed after native polyacrylamide gel electrophoresis as described in methods. A representative gel is shown. BSA and purified dihydrolipoyl dehydrogenase (E3) from Aeromonas caviae were used as negative and positive controls, respectively.

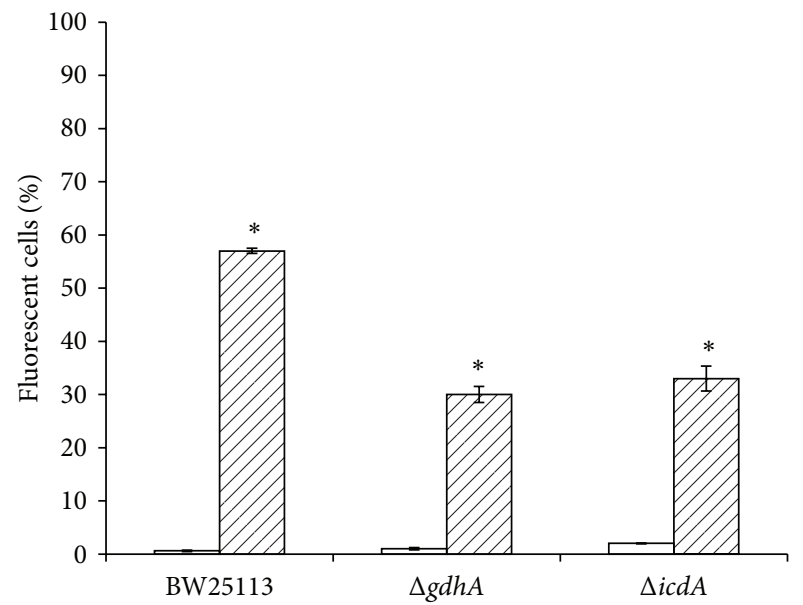

(a)

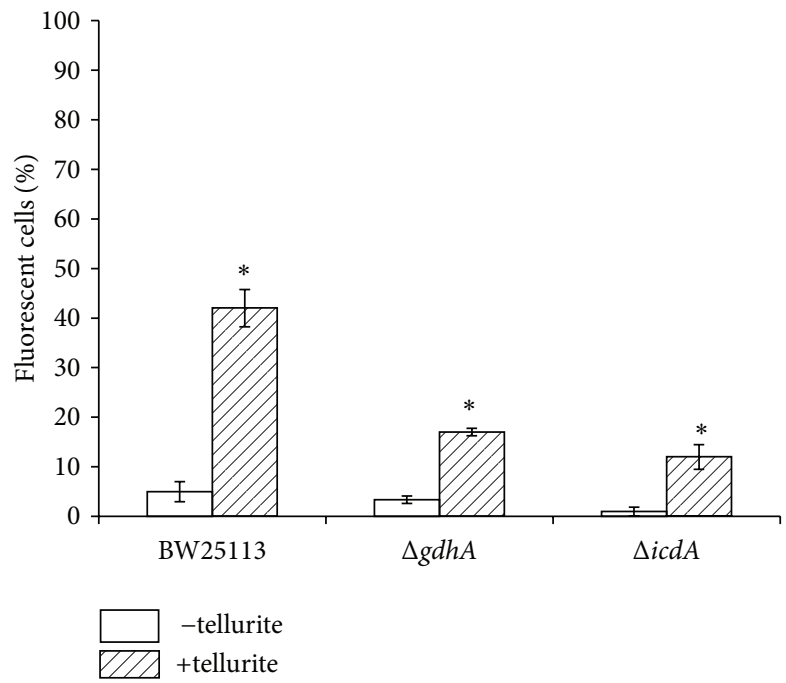

(c)

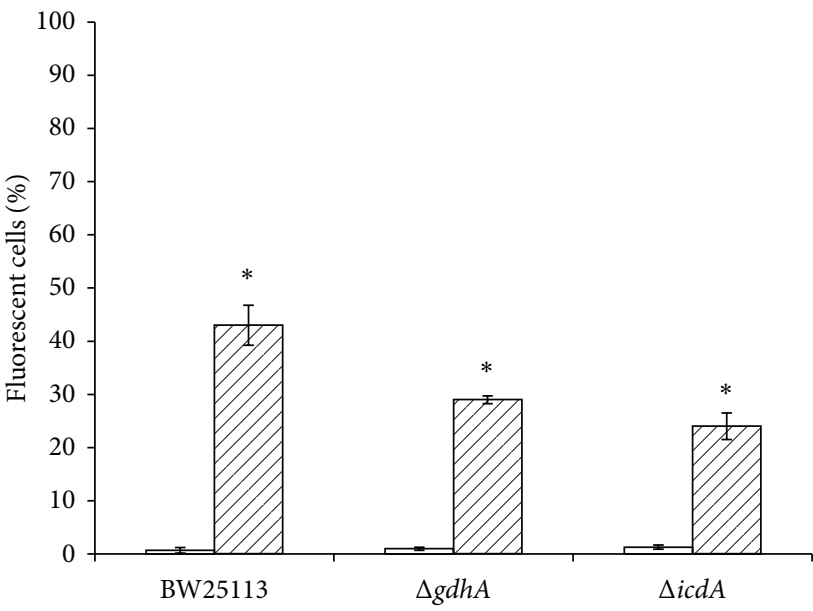

(b)

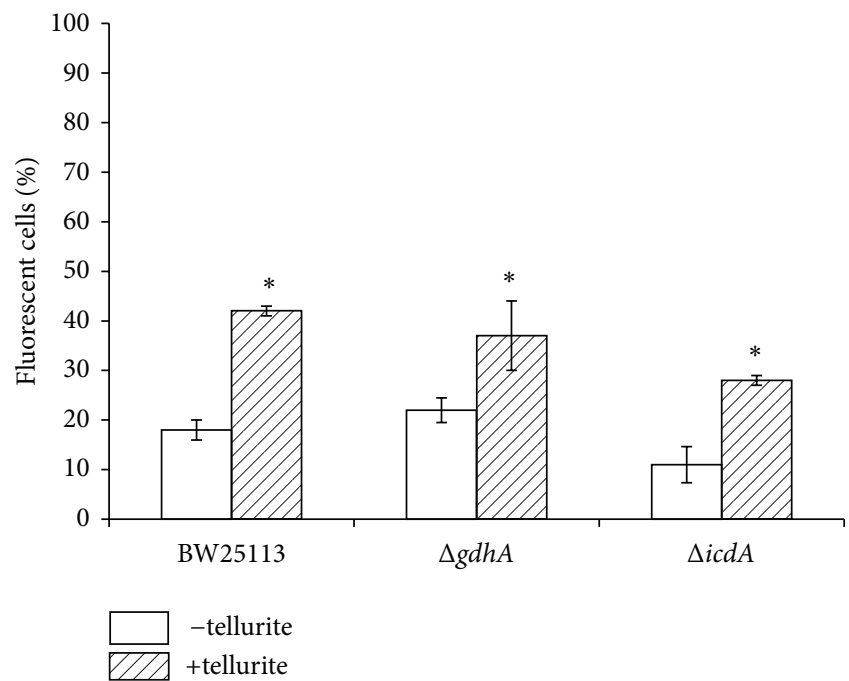

(d)

FIgURE 4: Total ROS and superoxide levels in tellurite-exposed E. coli. The indicated E. coli strains, exposed or not to tellurite, were assessed by flow cytometry to determine ROS as described in methods. ((a) and (b)): total ROS in LB-or M9-grown cells, respectively. ((c) and (d)): Superoxide levels in LB-or M9-grown cells, respectively. Numbers are the mean of 3 independent trials. *Significant regarding controls. 


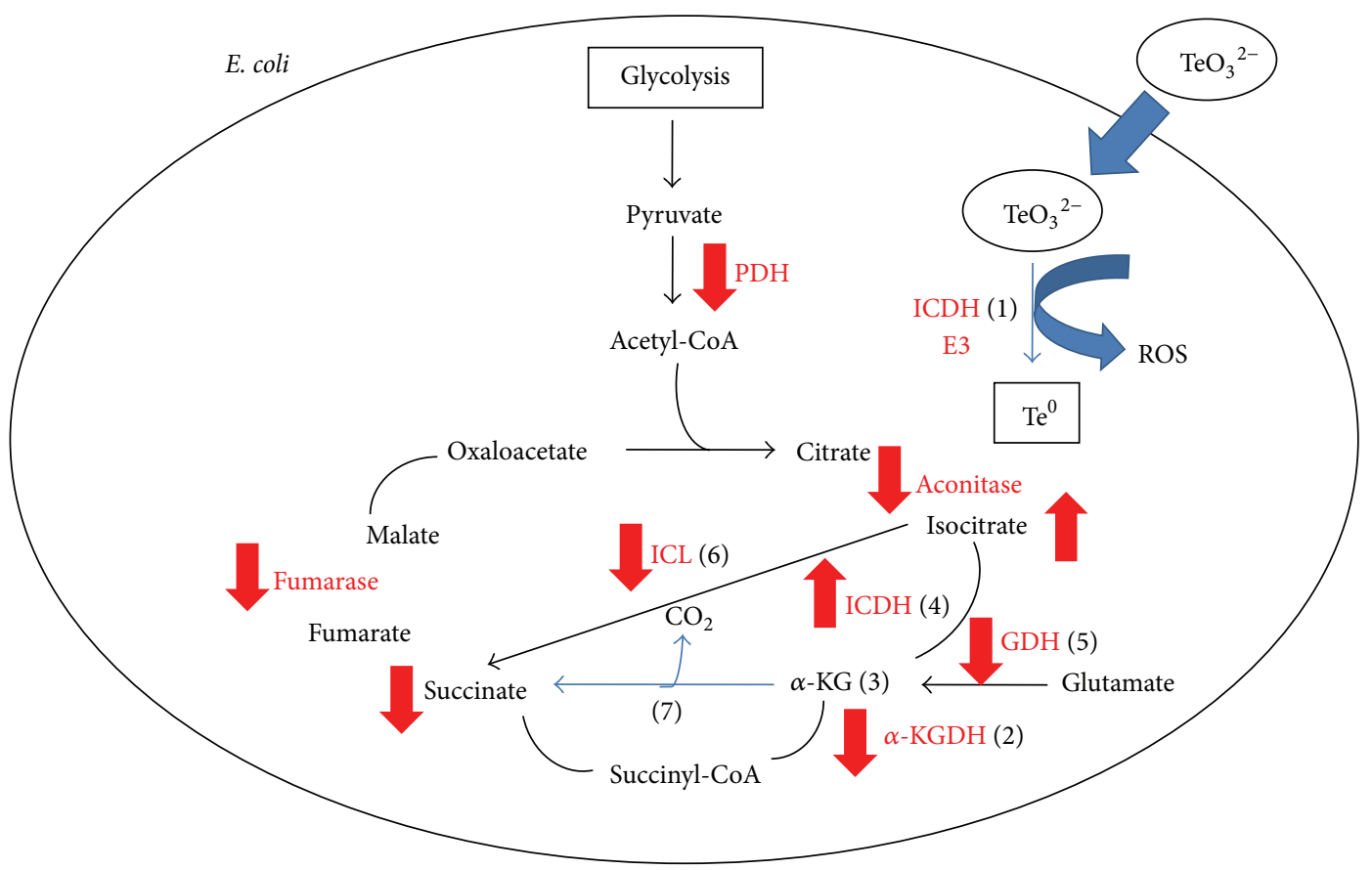

SCHEME 1: General model for the E. coli response to tellurite-mediated oxidative stress. See text for details.

PDH multienzyme complexes) [1], thus increasing intracellular ROS. E3's TR activity and the observed, diminished, sucA (encoding E1 from $\alpha$-KGDH) transcriptions provoke decreased $\alpha-\mathrm{KGDH}$ activity and $\alpha-\mathrm{KG}$ accumulation $[2,3]$. In addition, ICDH, GDH, ICL, PDH, fumarase, and aconitase activities are decreased when the cell faces tellurite [4-6], generating increased $\alpha$-KG content, which could be nonenzymatically decarboxylated in the presence of hydrogen peroxide [7].

\section{Conflict of Interests}

The authors declare that there is no conflict of interests regarding the publication of this paper.

\section{Acknowledgments}

This work received financial support from Fondo Nacional de Investigación Científica y Tecnológica (FONDECYT) Grant 1090097 and Dicyt-USACH (C.C.V.). CRG received a doctoral fellowship from Comisión Nacional de Ciencia y Tecnología (CONICYT).

\section{References}

[1] W. C. Cooper, Tellurium, Van Nostrand Reinhold Company, New York, NY, USA, 1971.

[2] J. C. Tantaleán, M. A. Araya, C. P. Saavedra et al., "The Geobacillus stearothermophilus $\mathrm{V}$ iscS gene, encoding cysteine desulfurase, confers resistance to potassium tellurite in Escherichia coli K-12," Journal of Bacteriology, vol. 185, no. 19, pp. 5831-5837, 2003.
[3] J. M. Pérez, I. L. Calderón, F. A. Arenas et al., "Bacterial toxicity of potassium tellurite: unveiling an ancient enigma," PLoS ONE, vol. 2, no. 2, article e211, 2007.

[4] V. Tremaroli, S. Fedi, and D. Zannoni, "Evidence for a telluritedependent generation of reactive oxygen species and absence of a tellurite-mediated adaptive response to oxidative stress in cells of Pseudomonas pseudoalcaligenes KF707," Archives of Microbiology, vol. 187, no. 2, pp. 127-135, 2007.

[5] V. Tremaroli, M. L. Workentine, A. M. Weljie et al., "Metabolomic investigation of the bacterial response to a metal challenge," Applied and Environmental Microbiology, vol. 75, no. 3, pp. 719-728, 2009.

[6] T. G. Chasteen, D. E. Fuentes, J. C. Tantaleán, and C. C. Vásquez, "Tellurite: history, oxidative stress, and molecular mechanisms of resistance," FEMS Microbiology Reviews, vol. 33, no. 4, pp. 820-832, 2009.

[7] R. J. Turner, Y. Aharonowitz, J. H. Weiner, and D. E. Taylor, "Glutathione is a target in tellurite toxicity and is protected by tellurite resistance determinants in Escherichia coli," Canadian Journal of Microbiology, vol. 47, no. 1, pp. 33-40, 2001.

[8] I. L. Calderón, A. O. Elías, E. L. Fuentes et al., "Telluritemediated disabling of $4 \mathrm{Fe}-4 \mathrm{~S}$ clusters of Escherichia coli dehydratases," Microbiology, vol. 155, no. 6, pp. 1840-1846, 2009.

[9] R. J. Mailloux, R. Bériault, J. Lemire et al., "The tricarboxylic acid cycle, an ancient metabolic network with a novel twist," PLoS ONE, vol. 2, no. 8, article e690, 2007.

[10] R. J. Mailloux, R. Singh, G. Brewer, C. Auger, J. Lemire, and V. D. Appanna, " $\alpha$-ketoglutarate dehydrogenase and glutamate dehydrogenase work in tandem to modulate the antioxidant $\alpha$-ketoglutarate during oxidative stress in Pseudomonas fluorescens," Journal of Bacteriology, vol. 191, no. 12, pp. 3804-3810, 2009. 
[11] T. Baba, T. Ara, M. Hasegawa et al., "Construction of Escherichia coli K-12 in-frame, single-gene knockout mutants: the Keio collection," Molecular Systems Biology, vol. 2, Article ID 2006.0008, 2006.

[12] A. A. Vlessis, D. Bartos, and D. Trunkey, "Importance of spontaneous $\alpha$-ketoacid decarboxylation in experiments involving peroxide," Biochemical and Biophysical Research Communications, vol. 170, no. 3, pp. 1281-1287, 1990.

[13] K. A. Nath, E. O. Ngo, R. P. Hebbel, A. J. Croatt, B. Zhou, and L. M. Nutter, " $\alpha$-ketoacids scavenge $\mathrm{H}_{2} \mathrm{O}_{2}$ in vitro and in vivo and reduce menadione-induced DNA injury and citotoxicity," The American Journal of Physiology-Cell Physiology, vol. 268, no. 1, pp. C227-C236, 1995.

[14] D. Clough and R. Bunger, "Protection by pyruvate against inhibition of $\mathrm{Na}^{+}, \mathrm{K}^{+}$-ATase by a free radical generating system: containing t-butylhydroperoxide," Life Sciences, vol. 57, no. 10, pp. 931-943, 1995.

[15] N. I. Fedotcheva, A. P. Sokolov, and M. N. Kondrashova, "Nonezymatic formation of succinate in mitochondria under oxidative stress," Free Radical Biology and Medicine, vol. 41, no. 1, pp. 56-64, 2006.

[16] C. A. Reinoso, C. Auger, V. D. Appanna, and C. C. Vásquez, "Tellurite-exposed Escherichia coli exhibits increased intracellular $\alpha$-ketoglutarate," Biochemical and Biophysical Research Communications, vol. 421, no. 4, pp. 721-726, 2012.

[17] B. Halliwell and J. M. C. Gutteridge, "Oxygen free radicals and iron in relation to biology and medicine: some problems and concepts," Archives of Biochemistry and Biophysics, vol. 246, no. 2, pp. 501-514, 1986.

[18] H. Eguchi, T. Wakagi, and T. A. Oshima, "A highly stable NADP-dependent isocitrate dehydrogenase from Thermus thermophilus HB8: purification and general properties," Biochimica et Biophysica Acta, vol. 990, no. 2, pp. 133-137, 1989.

[19] I. Fridovich, "Biological effects of the superoxide radical," Archives of Biochemistry and Biophysics, vol. 247, no. 1, pp. 1-11, 1986.

[20] J. H. Yang and J. W. Park, "Oxalomalate, a competitive inhibitor of $\mathrm{NADP}^{+}$-dependent isocitrate dehydrogenase, enhances lipid peroxidation-mediated oxidative damage in U937 cells," Archives of Biochemistry and Biophysics, vol. 416, no. 1, pp. 31-37, 2003.

[21] R. B. Helling, "Why does Escherichia coli have two primary pathways for synthesis of glutamate?" Journal of Bacteriology, vol. 176, no. 15, pp. 4664-4668, 1994.

[22] J. Sambrook and D. Russell, Molecular Cloning: A Laboratory Manual, Cold Spring Harbor Laboratory Press, Cold Spring Harbor, NY, USA, 3rd edition, 2001.

[23] M. M. Bradford, "A rapid and sensitive method for the quantitation of microgram quantities of protein utilizing the principle of protein dye binding," Analytical Biochemistry, vol. 72, no. 1-2, pp. 248-254, 1976.

[24] R. Singh, D. Chénier, R. Bériault, R. Mailloux, R. D. Hamel, and V. D. Appanna, "Blue native polyacrylamide gel electrophoresis and the monitoring of malate- and oxaloacetate-producing enzymes," Journal of Biochemical and Biophysical Methods, vol. 64, no. 3, pp. 189-199, 2005.

[25] F. Borsetti, F. Francia, R. J. Turner, and D. Zannoni, "The thiol:disulfide oxidoreductase DsbB mediates the oxidizing effects of the toxic metalloid tellurite $\left(\mathrm{TeO}_{3}^{2-}\right)$ on the plasma membrane redox system of the facultative phototroph Rhodobacter capsulatus," Journal of Bacteriology, vol. 189, no. 3 , pp. 851-859, 2007.
[26] M. E. Castro, R. Molina, W. Díaz, S. E. Pichuantes, and C. C. Vásquez, "The dihydrolipoamide dehydrogenase of Aeromonas caviae ST exhibits NADH-dependent tellurite reductase activity," Biochemical and Biophysical Research Communications, vol. 375, no. 1, pp. 91-94, 2008.

[27] M. Valdivia-González, J. M. Pérez-Donoso, and C. C. Vásquez, "Effect of tellurite-mediated oxidative stress on the Escherichia coli glycolytic pathway," Biometals, vol. 25, no. 2, pp. 451-458, 2012.

[28] E. M. Lohmeier-Vogel, S. Ung, and R. J. Turner, “In vivo ${ }^{31} \mathrm{P}$ nuclear magnetic resonance investigation of tellurite toxicity in Eschenchia coli," Applied and Environmental Microbiology, vol. 70, no. 12, pp. 7342-7347, 2004.

[29] E. S. Yang, C. Richter, J. S. Chun, T. Huh, S. Kang, and J. Park, "Inactivation of $\mathrm{NADP}^{+}$-dependent isocitrate dehydrogenase by nitric oxide," Free Radical Biology and Medicine, vol. 33, no. 7, pp. 927-937, 2002.

[30] S. M. Lee, H. J. Koh, D. C. Park, B. J. Song, T. Huh, and J. Park, "Cytosolic NADP ${ }^{+}$-dependent isocitrate dehydrogenase status modulates oxidative damage to cells," Free Radical Biology and Medicine, vol. 32, no. 11, pp. 1185-1196, 2002.

[31] S. M. Lee, T. L. Huh, and J. W. Park, "Inactivation of $\mathrm{NADP}^{+}$-dependent isocitrate dehydrogenase by reactive oxygen species," Biochimie, vol. 83, no. 11-12, pp. 1057-1065, 2001.

[32] J. H. Yang, E. S. Yang, and J. W. Park, "Inactivation of NADP ${ }^{+}$ dependent isocitrate dehydrogenase by lipid peroxidation products," Free Radical Research, vol. 38, no. 3, pp. 241-249, 2004.

[33] I. Batinic-Haberle and L. T. Benov, "An SOD mimic protects $\mathrm{NADP}^{+}$-dependent isocitrate dehydrogenase against oxidative inactivation," Free Radical Research, vol. 42, no. 7, pp. 618-624, 2008.

[34] Y. Zhang, N. Lu, and Z. Gao, "Hemin- $\mathrm{H}_{2} \mathrm{O}_{2}-\mathrm{NO}_{2}^{-}$induced protein oxidation and tyrosine nitration are different from those of SIN-1: a study on glutamate dehydrogenase nitrative/oxidative modification," International Journal of Biochemistry and Cell Biology, vol. 41, no. 4, pp. 907-915, 2009.

[35] A. Rehman and B. A. McFadden, "Lysine 194 is functional in isocitrate lyase from Escherichia coli," Current Microbiology, vol. 35, no. 1, pp. 14-17, 1997.

[36] R. D. Hamel and V. D. Appanna, "Modulation of TCA cycle enzymes and aluminum stress in Pseudomonas fluorescens," Journal of Inorganic Biochemistry, vol. 87, no. 1, pp. 1-8, 2001.

[37] M. M. Kabir and K. Shimizu, "Metabolic regulation analysis of icd-gene knockout Escherichia coli based on 2D electrophoresis with MALDI-TOF mass spectrometry and enzyme activity measurements," Applied Microbiology and Biotechnology, vol. 65, no. 1, pp. 84-96, 2004.

[38] W. O. Carter, P. K. Narayanan, and J. P. Robinson, "Intracellular hydrogen peroxide and superoxide anion detection in endothelial cells," Journal of Leukocyte Biology, vol. 55, no. 2, pp. 153-258, 1994.

[39] C. P. LeBel, H. Ischiropoulos, and S. C. Bondy, "Evaluation of the probe $2^{\prime}, 7^{\prime}$-dichlorofluorescin as an indicator of reactive oxygen species formation and oxidative stress," Chemical Research in Toxicology, vol. 5, no. 2, pp. 227-231, 1992.

[40] S. Kuramitsu, S. Okuno, T. Ogawa, H. Ogawa, and H. Kagamiyama, "Aspartate aminotransferase of Escherichia coli: nucleotide sequence of the aspC gene," Journal of Biochemistry, vol. 97, no. 4, pp. 1259-1262, 1985.

[41] R. E. Miller and E. R. Stadtman, "Glutamate synthase from Escherichia coli. An iron-sulfide flavoprotein," The Journal of Biological Chemistry, vol. 247, no. 22, pp. 7407-7419, 1972. 

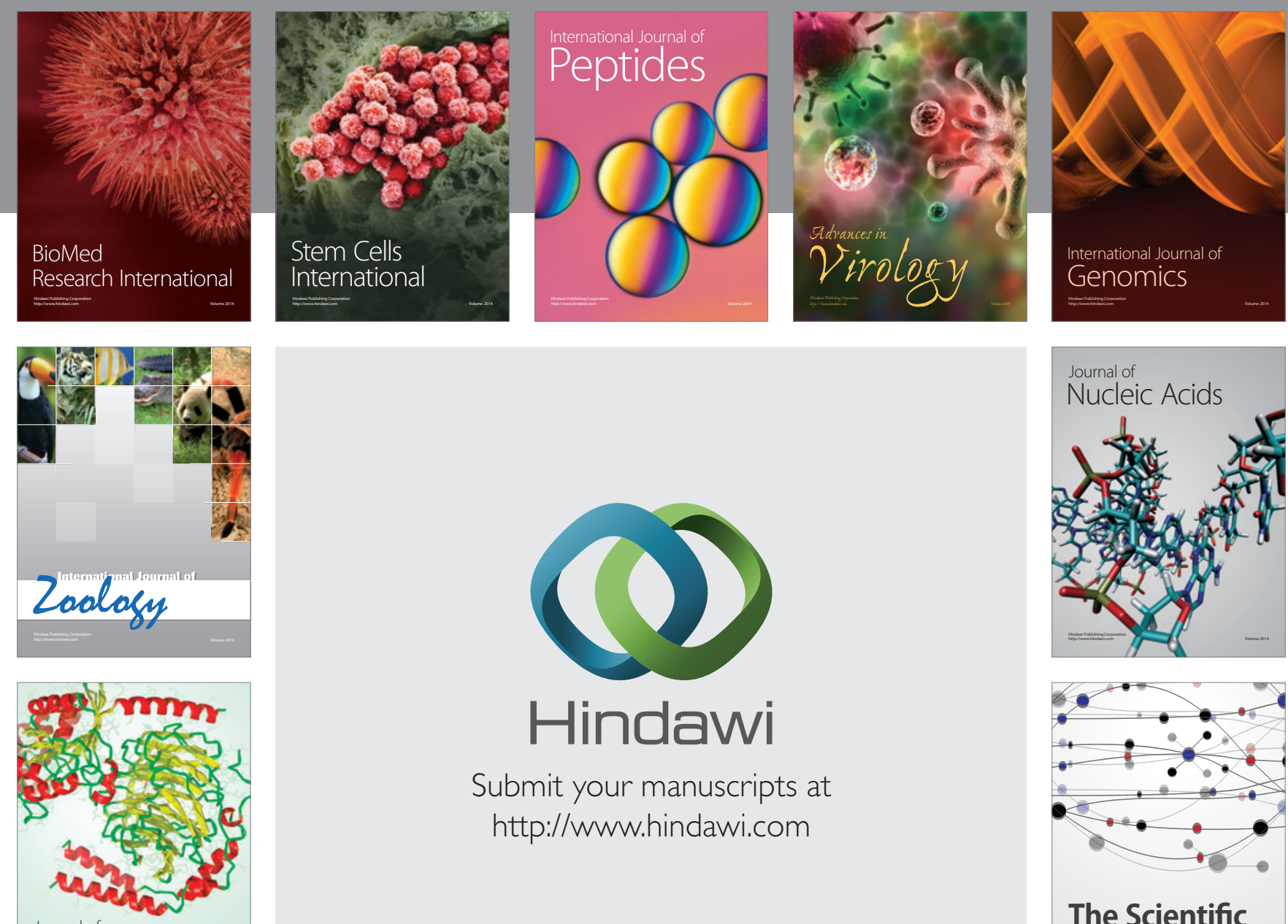

Submit your manuscripts at

http://www.hindawi.com

Journal of
Signal Transduction
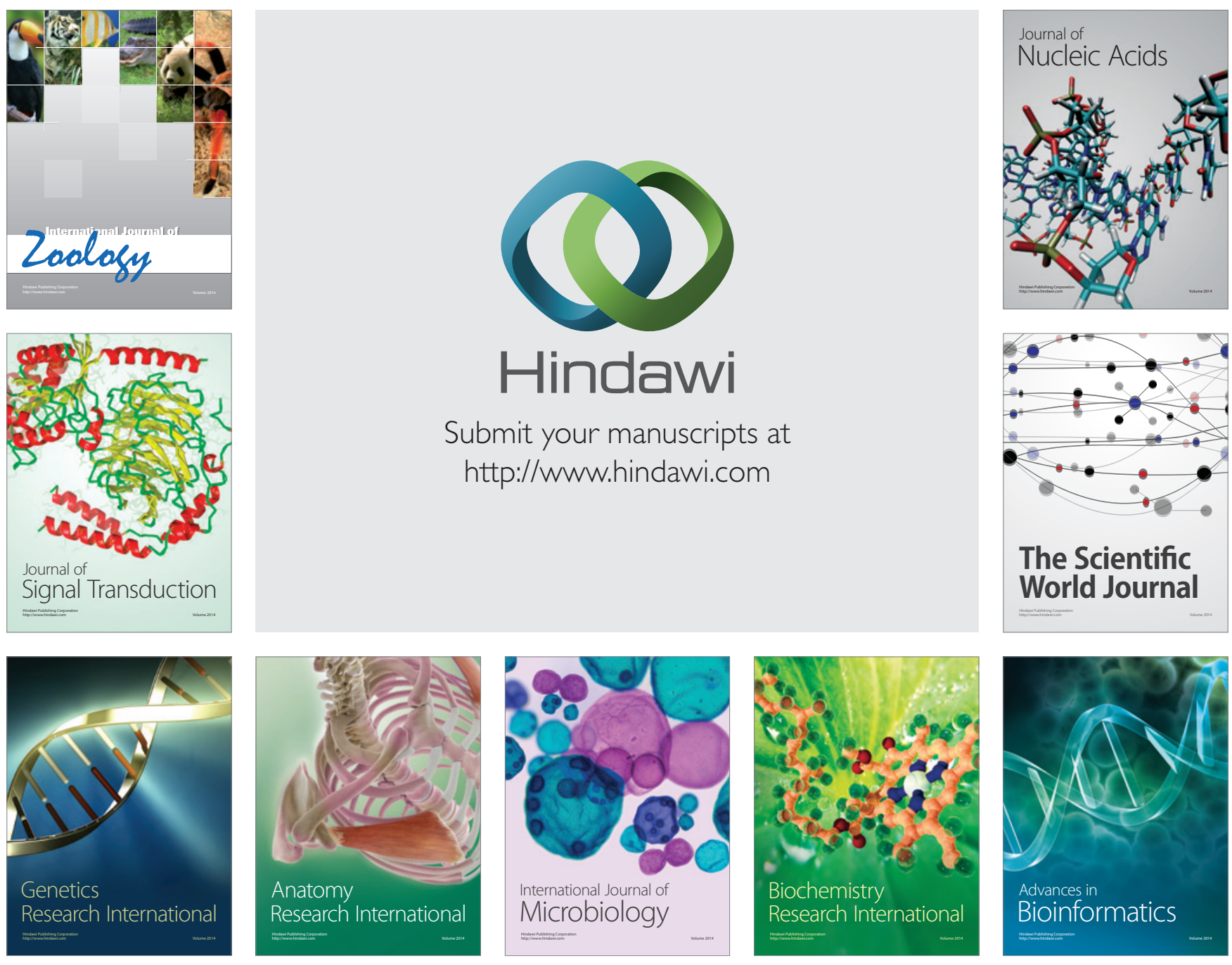

The Scientific World Journal
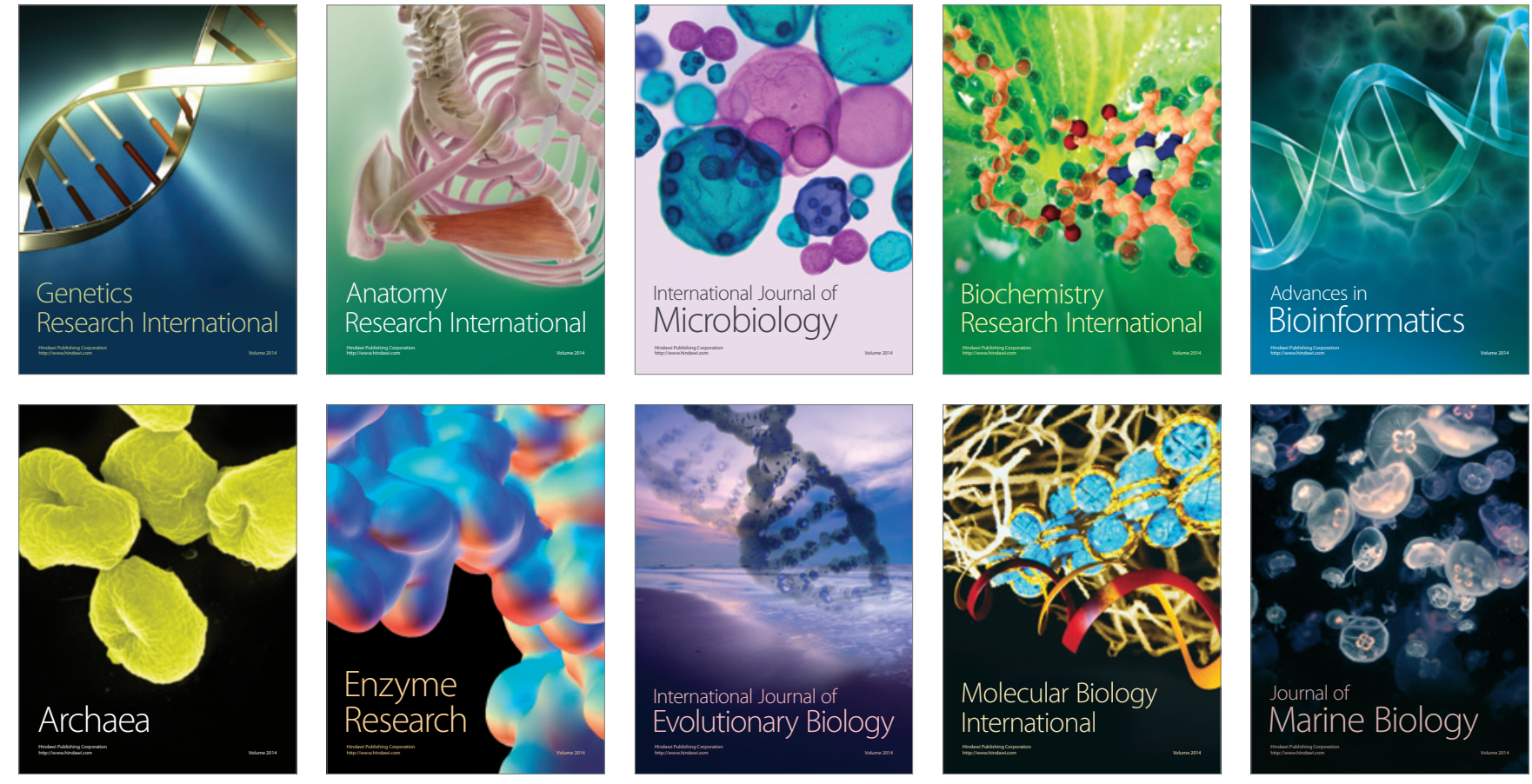